\title{
On the relationship between individual and population health
}

\author{
Onyebuchi A. Arah
}

Published online: 24 December 2008

(C) The Author(s) 2008. This article is published with open access at Springerlink.com

\begin{abstract}
The relationship between individual and population health is partially built on the broad dichotomization of medicine into clinical medicine and public health. Potential drawbacks of current views include seeing both individual and population health as absolute and independent concepts. I will argue that the relationship between individual and population health is largely relative and dynamic. Their interrelated dynamism derives from a causally defined life course perspective on health determination starting from an individual's conception through growth, development and participation in the collective till death, all seen within the context of an adaptive society. Indeed, it will become clear that neither individual nor population health is identifiable or even definable without informative contextualization within the other. For instance, a person's health cannot be seen in isolation but must be placed in the rich contextual web such as the socioeconomic circumstances and other health determinants of where they were conceived, born, bred, and how they shaped and were shaped by their environment and communities, especially given the prevailing population health exposures over their lifetime. We cannot discuss the "what" and "how much" of individual and population health until we know the cumulative trajectories of both, using appropriate causal language.
\end{abstract}

\section{O. A. Arah $(\bowtie)$}

Department of Social Medicine, Academic Medical Center, University of Amsterdam, PO Box 22700, 1100 DE Amsterdam, The Netherlands

e-mail: o.a.arah@amc.uva.nl; arah@ucla.edu

O. A. Arah

Department of Epidemiology, University of California, Los Angeles, School of Public Health, Box 951772, Los Angeles, CA 90095-1772, USA
Keywords Causality - Context - Ethics - Individual health - Life course · Population health · Theory of health

\section{Introduction}

"Population health" is a relatively new, rather fashionable term in the medical field. ${ }^{1}$ From its probable origins in Canada to its current use in the literature (Kindig and Stoddart 2003; Arah and Westert 2005), population health calls up images of non-individual health, at least in its literal meaning. Unsurprisingly, there is also "individual health" which is often seen as the complement of population health. Is population health merely the opposite of individual health? Do both represent core descriptions of health with respect to the individuals and societies? Both forms of health are, however, rarely analyzed together in the same papers, ${ }^{2}$ probably due to the prevailing dichotomy of medicine into clinical medicine (with its personal or

\footnotetext{
${ }_{1}$ A quick search of PubMed, the main literature indexing system in medicine, reveals that the term "population health" was used in the titles of 21, 27, 66, and 429 articles in the periods 1967-1976, 19771986, 1987-1996, and 1997-2006, respectively. This represents a 20fold increase from the 1967-1976 to the 1997-2006 periods. In contrast, the use of the term "individual health" or "personal health" in titles of article increased by only 9- or 3-fold, respectively, in the same period. Likewise, the use of "public health" barely doubled in that period.

2 This is, of course, only valid if we take both terms to refer to forms, types or states of health. As we will see later, population health, for instance, has been described as being more than just a summary term for the health of populations. In fact, population health has been called a field of study, perhaps to mirror the observation that the rather well-developed sister field, clinical medicine, deals with individual health (Kindig and Stoddart 2003; Coburn et al. 2003; Mechanic 2003; Pana and Muzzi 2004; Friedman and Starfield 2003).
} 
individual health purview) and public health (with its celebrated public or collective, ${ }^{3}$ and thus, population health purview) (Jamrozik and Hobbs 2002; Arah 2005; Arah et al. 2006). This binary approach to health and medicine has also played an important role in differentiating public health from personal medical care (Acheson 1988; Arah 2009; Arah et al. 2006; Verweij and Dawson 2007). Arguably, the birth of public health ethics as distinguishable from clinical ethics also rests on this dichotomization of medicine (see (Beauchamp 1975, 1983; Dawson and Verweij 2007). This dichotomization could even be traced back to the polarizing approaches of individualism and collectivism in the social sciences (O'Neill 1973; Weale 1981; Ball 2001). This if-it's-not-individual-it's-collective approach begs the question if that is all there is to a possible relationship between individual health and population health. Is it possible to study the relationship between individual and population health entirely in terms of the individual or the collective? And if at all, could the same concept of health be easily mapped onto the population level as at the individual level?

This article will argue that neither individual nor population health is identifiable or even definable without informative contextualization within the other. For instance, a person's health cannot be seen only in isolation but must be placed in the rich contextual web such as the socioeconomic circumstances and other health determinants of where they were conceived, born, bred, and how they shaped and were shaped by their environment and communities, especially given the prevailing population health exposures over their lifetime. We cannot discuss the "what" and "how much" of individual and population health until we know the cumulative trajectories of both, using appropriate causal language. Indeed, the complementary relationship between individual and population health evokes important socially relevant causal inferences about both having the duality of being determinants and outcomes over time, and within and between places or societies. The causal interpretations accorded both types of health flow directly from and are foundational to their definitional and measurement concerns.

\footnotetext{
$\overline{3}$ I use "collective" to refer to a definable group of people who share or are motivated by at least one common interest or work together to achieve a common objective. "Collective" may give an objectionable sense of an aggregation, yet it has a powerful way of reminding us that every society or collective is made up of individuals who are bound in a rich tapestry (Arah 2009).
}

Lonely lives: from the concept and collective context of health to individual health

Health as a concept is the focus of heated debates in the philosophy and medical literature. ${ }^{4}$ This literature is overwhelmingly concerned with the health of the individual and the medical or healthcare interpretations and interventions at the level of the diseased individual. In those instances, the term healthcare is often used to imply both personal medical care and public health. ${ }^{5}$ Currently, there are at least two major schools of thought on the concept of health, namely, the naturalist and the normativist theories of health (Boorse 1975, 1977, 1997; Schramme 2007; Nordenfelt 1986, 1995, 2007). Within the normativist theory, there are weak and strong normativist views (Khushf 2007).

The naturalist theory of health, which claims to be descriptive, value-free and consistent with evolutionary theory, states that an individual is completely healthy if and only if all her organs function normally, that is, given a statistically normal environment, her organs make at least their statistically normal contribution to her survival or to the human species survival (Boorse 1977, 1997; Schramme 2007). Thus, a healthy person is easily identified through objective medical investigation. According to normativist criticisms (Nordenfelt 2007), the naturalist theory of health lays too much emphasis on internal processes, biology and the absence of disease, effectively excluding extrabiological considerations such as "person," "intentional action" and "cultural standards." On the other hand, the normativist account, which espouses a value-laden evaluative approach holds that an individual is completely healthy if and only if she has the ability, given standard circumstances, to reach all her vital or essential goals in life (Nordenfelt 2007). This latter theory depicts a continuum where health accommodates disease, takes a holistic contextual approach, and instrumentalizes health in the larger scheme of vital life goals.

Interestingly both theories of health, to some extent, see disease in terms of relevant organ dysfunction. For instance, according to the naturalist account, a person has a disease if and only if at least one of her organs functions subnormally, given a statistically normal environment,

\footnotetext{
${ }^{4}$ See the March 2007 issue of the journal Medicine, Health Care and Philosophy for illuminating discussions of the concept of health.

5 As argued elsewhere (Verweij and Dawson 2007; Arah 2005, 2009; Arah et al. 2006), (personal) medical care is best used to connote the more individually oriented healthcare services, usually involving oneon-one patient-physician interactions, whereas public health-in addition to its health of the public or population health meaning-is perhaps best described as the organized efforts aimed at collective mechanisms of ensuring the health of the collective or the healthful context for the interacting individuals within the collective.
} 
while the normativist theory asserts that a disease is a state or process in which the individual has at least one organ involved in any state that tends to reduce the individual's health. Although engaging in a debate on the merits of each theory of health is beyond the scope of this article, I want to point out that both theories appear to take the context or circumstances or environment of any health-disease continuum as merely observed or passive, not active, interventional or causal. ${ }^{6}$ Yet, we all know that many diseases $^{7}$ arise from the complex interplay of the person and her context, be it social, psychological, physical, economic or not (Lalonde 1974; Evans and Stoddart 1990; van Oers 2002; Arah et al. 2006). My argument is that any concept of individual health must emphasize the role of the person's circumstances in health maintenance or even in disease causation, fleshing out the imbalance between the internal and external functionings. This imbalance is reflected in a recent attempt to characterize the origins of human disease (Mackenbach 2006):

In all its manifestations, human disease is a reaction of organisms to, and/or a failure to cope with, one or more unbalancing changes in their internal environments. These are caused by one or more unfavourable exchanges with their external environments and/or failures in the structural and functional design of organisms. In the final analysis, human disease is attributable to the dependence of organisms on a fundamentally hostile external environment and to unfortunate evolutionary legacies.

\footnotetext{
${ }^{6}$ To my understanding, both the naturalist and normativist define probability of health, $\operatorname{Pr}(H)$, in terms of "given the biostatistically normal environment" (Boorse 1997) or "given standard circumstances" (Nordenfelt 2007), what I will call the context C: thus, health probability is, simply put, $\operatorname{Pr}(H=\mathrm{h} \mid C=\mathrm{c})$. However, this $\operatorname{Pr}(H=\mathrm{h} \mid C=\mathrm{c})$ is not the same thing as $\operatorname{Pr}(H=\mathrm{h} \mid \operatorname{do}\{C=\mathrm{c}\})$, that is, what health would be if the context were seen as an external intervention or a causal one influenced by, say, active change of environment, lifestyle, interactions, and policies. Thus, $C$ is not merely observed in the definition for it to be relevant to health, it must be causally relevant (hence, the "do $\{C=\mathrm{c}\}$ " calculus). The probability expression $\operatorname{Pr}(H=\mathrm{h} \mid \mathrm{do}\{C=\mathrm{c}\})$ is isomorphic to the potential outcomes or counterfactual framework of causality envisaged by Hume (1748) and Lewis (1973). For instance, allowing context or "given standard circumstances" to take on a causalinterventionist meaning is important for appreciating what Tolu's health would be if she moved from her deprived circumstances in the developing Nigeria to the safer affluence of England: Tolu's context is thus not only observed but was done by her "changing" her context. This topic of causality as interventionist even in so-called observed context versus mere description of observations as a substitute for causal inference using non-experimental data is the subject of recently renewed technical and philosophical interests (Spohn 1980; Pearl 1995, 2000; Greenland 2000; Maldonado and Greenland 2002; Spirtes et al. 1993).

7 To the determinist, this might well include all diseases.
}

To be sure, there is more to health than mere absence of disease. An emphasis on the notion of the context-or what naturalists call the "statistically normal environment" or the normativists call "standard circumstances"-is needed to understand how health is promoted in a positive sense, maintained or disrupted, and to give meaning to the theory of health as a continuum rather than as a binary concept of health versus disease. Three important properties characterize the context of health and disease. Firstly, this context has to be seen in terms of internal-external balance between the individual and her context or environment. Secondly, the contextual balance must be causal in nature, at least in the counterfactual sense of being capable of leading to a different individual health if the balance were altered (Lewis 1973; Greenland 2000; Maldonado and Greenland 2002; Pearl 2000). Hume (1748, p. 115) defines a cause to be "an object, followed by another ... where, if the first object had not been, the second had never existed." An important aspect of this view of causation is its counterfactual concept: a certain outcome event (the "second object," or effect) would not have occurred if, contrary to fact, an earlier event (the "first object," or cause) had not occurred (Maldonado and Greenland 2002; Greenland 2005). Thirdly, context is cumulative. Early life insults can and have been known to persist into adult life (Kuh and Ben-Shlomo 2004), and to curb the ability to pursue life's vital goals (Nordenfelt 1995) or what one may have reason to value (Sen 1985, 1992). The foregoing properties redefine the context of health as being not merely observed but actually causative or determinant of the level, dynamics and distribution of health. This is in line with the popular use of the phrase "determinants of health" in the health literature (Arah and Westert 2005). ${ }^{8}$ As we will see later on, the revitalization of the context part of the health concept allows us to evaluate the health relationship between individuals and across populations, in essence, linking individual and population health.

\section{Populations without individuals: from the concept of health and context of interacting individuals to population health}

Health is a very individual affair. Or is it? When Tolu broke her leg in a motor accident on a precariously narrow road in her home town in south-west Nigeria, it seemed fair to say it was Tolu's health, not that of her community or any such

\footnotetext{
${ }^{8}$ Unfortunately, the term "determinants of health" may leave an unsavory feeling that the relationship between individual (or even population) health and its context is rigidly deterministic. Although I personally see a role for determinism, I temper this to mean no more than probabilistic determinism, within a counterfactual framework (Hume 1739, 1748; Lewis 1973; Pearl 2000).
} 
collective to which she belonged, that was primarily compromised. It turned out that Tolu, who was a publicly employed physician, in her deprived town with few doctors, was on her way to the hospital, to respond to an emergency call from the local hospital to help out on a particularly busy day. She was supposed to be enjoying her off-duty rest on that day. Typically, she would attend to a lot of patients, many of whom suffered from infectious diseases, were malnourished, and had been victims of road traffic accidents, and so on. Being incapacitated by her injury, she was unable to attend to her patients who must now increase the workload of other already over-stretched doctors. The infants among the patients suffered disproportionately; they were more vulnerable and had illnesses that rapidly consumed them without prompt care. Unknown to most, the hospital was unable to save a number of such vulnerable patients who would have been seen by Tolu had she not been reduced to a patient herself by a complex web of social and personal circumstances. Her health was intricately linked to the health of her fellow townspeople. Not only did they suffer as a result of her inability to be a physician to them, but also they were subject to what (dangerous roads, deprivation, and other "standard circumstances") shaped Tolu's health and her pursuit of her vital goals (which included being able to cycle, being an attending physician to the needy, and so on). Actually, she chose to become a physician as a result of the telling experiences of growing up in the town's squalor. So, their lives, well-being and health, were co-dependent, at least on some level. In a sense, it was difficult for Tolu to remain healthy in a town full of so many suffering people. Indeed, it would be difficult to conclude that this town's population health was ideal, full or complete. The interacting individuals who made up the collective were often at risk of lessthan-full health, largely due to the collective "standard circumstances" they lived in, a context they sculptured or was sculptured for them in some way, and which also sculptured who and what they became.

Admittedly, the foregoing illustration is a little dramatized. It serves its purpose nonetheless: health is not entirely individual; it is relative to the individual's context, which in turn is fashioned out of the interactions that exist between members of any defined collective whose health (read: population health) is defined by the health and context of its members. The circularity of this concept and argument is not lost on us. Many diseases such as allergic, cardiovascular, and even genetic ${ }^{9}$ disorders seem to have

\footnotetext{
9 Take the example of the autosomal recessive hereditary/genetic condition known as phenylketonuria (PKU), diagnosable in newborns. It results from a gene mutation on chromosome 12, leading to absent or reduced activity of the enzyme needed to process one of the essential amino acids, phenylalanine (present in many cereals, cocoa products, egg, fish). Theoretically, if a child with PKU were to be born in a context where phenylalanine did not exist in staple foods-
}

contextual antecedents (Mackenbach 2006). And these contextual causes, determinants or facilitators tend to accumulate from, probably, before conception and birth through adult life (Kuh et al. 2003; Kuh and Ben-Shlomo 2004). We will return to this issue of life course and causal context of health in a population shortly.

First, I want to broach two implicit views of population health: the simply-the-sum-of-the-parts and the greaterthan-the-sum-of-the-parts views. The former-hopefully with a dwindling proponents base-sees population health as no more than a summary of health, aggregated across individuals within a population (see for instance, the debate and work on designing summary measures of population: (World Bank 1993; Murray and Lopez 1994; Murray et al. 1994, 2001, 2002; Murray and Evans 2003; Murray 1994; Anand and Hanson 1997, 1998; Institute of Medicine 1998; World Health Organization 2000; Williams 2000; Mathers et al. 2003, 2004)). Under this view, summary measures of population health (SMPH) represent aggregated, singular indices of the quantity and sometimes distribution of health in a given population. These measures combine data on mortality and morbidity, including disability, obtained from the population in question or extrapolated from "similar contemporary" populations. The idea is that both the quantity and quality of life that an individual born into such a population could expect to enjoy can be captured by measures such as healthy life expectancy (HALE) and disability-adjusted life years (DALY). These measures are commonly used in global health and national health policy circles. Critics have pointed that some of these metrics are not necessarily equitable or particularly suitable for the health policies they are purported to support:

[Disability-adjusted life years or] DALYs are an inequitable measure of aggregate ill-health and an inequitable criterion for resource allocation. Through age-weighting and discounting, they place a different value on years lived at different ages and at different points in time. They value a year saved from illness more for the able-bodied than the disabled, more for those in middle age-groups than the young or the elderly, and more for individuals who are ill today compared with those who will be ill in the future. We regard such valuations to be inequitable both for the

Footnote 9 continued

instead a related amino acid, tyrosine, which replaces phenylalanine in the metabolic pathway in the human body, were present- then it is difficult for the disorder to be suspected in the absence of mandatory testing. Therefore, this child could easily grow up without the PKU disease label. Thanks to the child's new extraordinary context, she could remain healthy although her bodily functions are easily engaged in a process that tends to reduce her health. Notice that her new context is far from being standard, even relative to her human species. 
exercises of measuring the quantity of ill-health and for resource allocation. For resource allocation equity requires giving priority to the claims of the disadvantaged, which cannot be achieved by using the restricted information set of the DALY (Anand and Hanson 1998).

The second implicit view of population health, the greater-than-the-sum-of-the-parts account as pursued in this article, would see population health as the indivisible health experience of a collective of individuals, where this collective is taken to be distinguishable from a mere collection or summation of individuals. ${ }^{10}$ The context would be seen as so defining and powerful that simple aggregations of health into singular measures would miss the richer information present in the context that shapes current and future health of the collective and of its individual members. At a minimum, population health should be measured in multidimensional terms, rich in information for different purposes and interpretations. Greenland recently underscored this requirement as follows:

My intention in raising these issues is not to offer a solution to a specific summarization problem. Rather, it is to remind those facing a choice among measures that candidates need not (and, for policy purposes, should not) be limited to unidimensional summaries. While our ability to think in several dimensions is limited, it can be improved with practice. That practice has proven crucial in attacking problems in physics and engineering, and there is no reason to suppose it is less important in tackling more complex social policy issues. In instances in which many different people must make informed choices based on the same scientific data, but with different values, multidimensional measures are essential if we are to provide each person and each executive body with sufficient information for rational choice (Greenland 2005).

It is clear that how population health is measured is dependent on how it is conceptualized. If population health were seen only as aggregate health of a group, then unidimensional metrics such as HALE and DALYs might suffice. If, however, population health were conceived as a deeply contextual and causally charged notion, then metrics that went beyond the descriptive and dealt with the predictive, explanatory and evaluative would be needed

\footnotetext{
10 This indivisibility and inseparability of individuals and their context must be seen in such a way that the same collective of individuals could not be moved from their current context to a new one without changing the identity, health, interactions, and well-being of the collective.
}

(McDowell et al. 2004). Is this how population health is conceived in the public health literature? Population health as a concept of health has been defined as "the health outcomes of a group of individuals, including the distribution of such outcomes within the group" (Kindig and Stoddart 2003). Additionally, as a field, population health is said to address how and why some groups of people are healthy and others are not (McDowell et al. 2004; Evans and Stoddart 2003). The late Geoffrey Rose once described the population [health] strategy as

“... the attempt to control the determinants of incidence, to lower the mean level of risk factors, to shift the whole distribution of exposure in a favourable direction. In its traditional 'public health' form it has involved mass environmental control methods; in its modern form it is attempting (less successfully) to alter some of society's norms of behaviour” (Rose 1985).

Although the term population health could mean health outcome or health determinants in relation to public health outcomes or both, public health specialists mostly spend their time trying to influence the determinants or the socalled root causes of population health. This population health approach is quite old although there is no definitive history of this approach, with recent historic applications seen in the works of Jerry Morris and Richard Titmuss (Szreter 2003) and in the seminal Lalonde model (Lalonde 1974; Evans and Stoddart 1990).

At its simplest level, the health determinants or Lalonde model states that health has four classes of determinants: lifestyle, environment, human biology, and healthcare. This rather simple model was rather well-received, with no one seriously challenging the view that how we lived, where we lived, who we were (born), and the care we used all shaped our health. As Evans and Stoddart (1990) noted, the policy response was not entirely clear given that one possible policy interpretation could have been that health was a personal choice. This is something that could be heard echoing in the corridors of many North American and European ministries, given the rise of consumerism, performance disclosure, market mechanisms and the information age in nearly all public policy areas. If anything, public policy on health missed the point about the health of populations being contextual, a reflection of the complex interplay of lifestyle, environment, human biology and even healthcare. Recently, a global Commission on Social Determinants of Health was launched by the World Health Organization to focus health policies on the social context of health and inequalities (Lee 2005; Marmot 2006; Irwin et al. 2006). I can only hope the renewed interests will see the context of population health as both a means and an end, not just another series of inputs for attaining and subsequently aggregating health across 
members of a group. The context of population health comprises so much diversity, meaning and information which must be factored into any health evaluation exercise or intervention that seeing context as only given circumstances is to render the very concept of health of a person and of a group impotent.

\section{The life course}

A crucial prerequisite for defining individual health and population health in terms of their context is that context must be dynamic and causal. Dynamic implies that context is not stationary. Even habitual lifestyles are rarely stationary; they are subject to the enabling environment and resources that feed such habits. Human biology is subject to numerous factors like micro-organisms, radiation, accidents, and so on. Individuals are born; they develop from childhood, adolescence through adulthood, learning the language and ways of life of their parents, imbibing their tastes, experiences, music, dance, art, and interacting with other people. They fall ill, survive, marry, have their own children, live with the marks of their experiential journey through life, and are continuously molded by their context as they search for and define who and what they become. Social epidemiologists only recently discovered this life course interpretation of the health, well-being and over-all context of human beings, something that was already known for many years to psychologists, sociologists, anthropologists, biologists, and demographers (Kuh and Ben-Shlomo 2004). Life course

...epidemiology studies long term effects on later health or disease risk of physical or social exposures during gestation, childhood, adolescence, young adulthood and later adult life. It aims to elucidate biological, behavioural, and psychosocial processes that operate across an individual's life course, or across generations, to influence the development of disease risk (Kuh and Ben-Shlomo 2004).

Parents' social class, behaviors, wealth, education, and other childhood factors like cognitive and psychosocial developments have all been shown to determine who stays healthy, falls ill or dies prematurely in adult life (Kuh and Ben-Shlomo 2004; Case et al. 2005). If lifetime circumstances so evidently mold health and well-being and also subsequent social and other life circumstances in such cumulative ways, why must the health of persons and groups be seen as individual or concerted organ functioning given normal environment or circumstances? What is normal? Which environment? The currently observed one? Or the one that has accumulated over the life course and may remain a harbinger of well-being in years to come?
Neither individuals nor collectives can be understood in only cross-sectional, one-time views. All through their lifetimes, individuals become the collective just as the collective becomes them. And collectives age across generations of its members, evolving and defining and being defined through cumulative and adaptive experiences, events, and history. In all these, an individual still retains her individual, distinctive identities that evolve over time. This individualism within a collective should not be mistaken with the ordinary usage of individualism that seems to suggest a whiff of unsociability, but should be taken as the sort that forms the basis for an extensive concern for others (Appiah 2005). This concern is the type needed throughout life to build a context worthy of individuality, freedom and collective well-being and health.

\section{Healthy individuals, healthy populations}

So far, I have argued that neither individual nor population health is easily separable from the other. Even when they are considered separable, as approaches to health, rather than health concepts, Geoffrey Rose would seem to choose the population approach because he was a strong believer in the context and distribution of health and its causes (not that he would sacrifice individuals to achieve his objectives) (Rose 1985, 1992). One might ask if the link between individual and population health could then be construed to imply that unhealthy individuals could not be found in healthy populations and vice versa. Instances of incongruity between individual and population health may be best understood by considering a possible categorization of the individual-versus-population health relationship.

Therefore, borrowing terminology from epidemiologic methodology (Copas 1973; Greenland and Robins 1986), I can classify the individual-versus-population health relationship into four categories:

1. Immune: individual health remains good irrespective of the population health or context

2. Causative: individual health is boosted in favorable population health or context

3. Preventive: individual health is compromised when population health or context is unfavorable

4. Doomed: individual health is compromised irrespective of the population health or context.

Categories 1 and 4 would be rare under our considerations and in real life. They would include genetic diseases (category 4) which progress irrespective what is done or experienced in the collective or medicine. The two middle categories would be far more realistic and common. A category 2 illustration: If along with the growing physician emigration (Arah et al. 2008), Tolu were to move from her 
impoverished circumstances in Nigeria to a safer suburb somewhere in England, her health would no longer be what it was or would have been back in her hometown. She and her family might not only enjoy the healthful experiences of their new context, they might also acquire other nonhealth experiences and tastes which might subsequently redefine their immediate and long-term well-being. She, and in particular her children, would have escaped from a context where their life expectancies might have been the odd forty-something years to a place where they could live well into their seventh decade or longer. This would contrast with a category 3 scenario where Jane, a Brit, who might have lived to be an octogenarian in England, would end up cutting her life short in her thirties by moving to a mosquito-infested Nigeria without proper anti-malarial prophylaxis or by being involved in a rather common road traffic accident there. Similarly, it is very difficult to imagine populations that could be called healthy if the context for health is heavily compromised and individual members of the collective are at constant risk of dangerous exposures and events. It then seems to me that the relationship between individual and population health is a matter of ubi mel ibi apes-where there is honey there are bees.

To be sure, health is not entirely relative. It will be selfdefeatist to assume a rigidly relativist view. Such a view would excuse the unfortunate morbidity and mortality suffered by millions of children in deprivation in Africa. After all, their "fate" could be dismissed as their context. However, this would imply denying a partial absolutist notion of health (for instance, for these children not to be malnourished, to enjoy good health, and not be stricken dead before age five). In a purely relativist view, we could easily miss a widespread compromise of health in a context where health was already poor because we might erroneously infer that the relative distribution of health remained unchanged. The absolutist core of health implies that whenever health is compromised to the extent that functioning is obstructed that there is ill-health, no matter what the relative picture looks like. It is on this absolutist core of health that a relativist layer of the enabling context of health should be built. The relationship between individual and population health resides mostly in this relativist layer, although it requires the absolutist notion of health to exist in the first instance.

Without the informative contextual characterization of health at the individual or population level, there is little insight being gained by saying a person or a community is healthy. A possible criticism here is that this contextual reinterpretation of individual and population health includes almost every well-being oriented activity under the rubric of health. True, but this fear of all-inclusiveness that has already been leveled against the normativist school is not embarrassing. If anything, it is refreshingly bold to attempt to elevate the concept of health to the level of human wellbeing. If health is so integral to the notion of well-being and to the ability to conduct the life one may have reason to value (including achieving one's vital goals) (Nussbaum and Sen 1993; Nordenfelt 1995, 2007), then it is not surprising that the boundaries of health can easily encroach on the boundaries of well-being and life as a whole. After all, health represents both functioning (the achieved) and capability (the achievable): a means to life's other vital goals or capabilities as well as an end in itself (Sen 1985; Nussbaum and Sen 1993).

I suspect that when some philosophers reject such ambitious notions of health, they are merely concerned with the overuse or abuse of possible responses or interventions to deal with not being in "full health": a fear of medicalization. However, I think such criticisms miss the subtle but important distinctions between the boundaries of health (and thus, health need) and the boundaries of healthcare (and thus, healthcare need). ${ }^{11}$ Health need depicts the shortfall in ideal health (in some sense, a gradual progression from the completely healthy end of the health spectrum to the disease end), whereby the shortfall and context combine to hinder the ability to flourish to a degree important to the individual. Healthcare need, on the other hand, alludes to a shortfall in health which inhibits a person's ability to flourish and which is only amenable to healthcare or organized medicine. Not every health need would become a healthcare need. In this sense, health need subsumes healthcare need, not the other way around. Suffice it to say that while it is necessary to avoid medicalization, there is little reason for a concept of health to be bounded mainly by this medicalization avoidance or by any narrowly defined interpretation of what medicine is. Medicine is largely a socially constructed response and therefore secondary, whereas health is more fundamental

\footnotetext{
11 From an economic societal perspective, healthcare need has been defined "as the minimum amount of resources required to exhaust a person's capacity to benefit" (Culyer 1995). Culyer proposed the following conditions for recognizing healthcare need: (i) that its value-content be up-front and easily interpretable; (ii) that it be directly derived from the objective(s) of the health care system; (iii) that it be capable of empirical application in issues of horizontal and vertical distribution; (iv) that it should be service and person specific; (v) that it should enable a straightforward link to be made to resources; (vi) that it should not, if acted upon as a distributional principle, produce manifestly inequitable results. Culyer's definition has all the good elements of the capacity to benefit notion, an observation that should please those who object to "medicalization" on safety and effectiveness grounds. It also quantifies the resources that are needed, a feature that ought to please those who fear "medicalization" on inefficiency grounds. Tolu and Jane, say, might have equal health needs and yet different healthcare needs, or different health needs but the same healthcare needs. If at equal health needs, Tolu required more resource-intensive healthcare, Culyer would say that Tolu had higher healthcare need than Jane.
} 
and therefore prior. Nordenfelt has discussed some of the notions of medicine as health enhancement in both narrow and broad senses (Nordenfelt 1998, 2001).

For now, I will submit that the prevailing dichotomization of medicine-and its associated fields including (bio)ethics-into clinical medicine and public health aspects is erroneous, inefficient, and outdated, if not unethical. This criticism can also be leveled against the duality I have been discussing, namely, individual versus population health. Such binary views which seem to pervade almost all of public policy on health fail to use the rich information and interpretations that stem from a more comprehensive approach to health over the life course (i) of the individual within the collective and (ii) of the collective of interacting individuals.

Many questions remain unanswered. I invite the reader to consider them: If the concepts of individual versus population health are so intimately interwoven, why do bioethicists see the need to separate public health ethics from main stream bioethics? Is it to give ethical considerations to, say, distributional issues that would otherwise be difficult at the individual or clinical level? Or are we young public health ethicists just busy building a parallel dichotomy similar to that seen between clinical medicine and public health, by way of argumentum ad verecundiam? Further, given the mounting evidence that health is compromised early in life and that the insults are borne forward into adult life and beyond and ultimately lead to expensive healthcare, why do health policies still concentrate overwhelmingly on healthcare in adulthood? While we are at it, must healthcare represent the standard policy response to health problems, in effect being what Norman Daniels once called the ambulance at the bottom of the cliff after the free fall through life?

\section{Conclusions}

This article has argued that the relationship between individual and population health is one that is entrenched in the contextual definition of health and its life course causes. I have made an attempt to derive this relationship based on the concept of health (if we were to continue pursuing such a concept anyway) by including a population perspective on health. I emphasized the role of the "context" component of any notion of health, that is, the role of the "standard circumstances" or the so-called "statistically normal environment." I then argued that this context is both individual and collective in nature, in largely inseparable ways, and that context must be causally seen across the life of an individual and the life of the collective. The meanings of both individual and population health lie in this revitalized life course and causally defined context, and have implications for how we measure and analyze health at all levels. Armed with the reasoned scrutiny and the unresolved complexity of the concepts, I invite philosophers and other scientists to revisit the definitions of individual health and population health if the notions are to carry any more weight in ongoing discourses in public health, healthcare, and bioethics. I can only hope that this article will stimulate further debates on individual and population health concepts and on their associated policy-relevant fields. One conclusion of this article, for now, is that health, be it individual or population health, can be very context-dependent. After all, prior to the accident, Tolu may have been absolutely healthy from her personal experiential point of view, but she was still contextually unhealthy, relatively speaking.

Acknowledgments I thank the following for their helpful comments: Julia van Ooststroom, Thomas Plochg, Ines Rupp, Karlijn Overeem, J. Lennert Veerman, and the participants of the Special ESPMH/InterPHEN Symposium at the XXIst conference of the European Society for Philosophy of Medicine and Health Care (ES$\mathrm{PMH}$ ), at Cardiff, Wales. I am grateful to Angus Dawson and Søren Holm for inviting me to be a panelist and to give a talk on "The Definition of Public Health" at that symposium. I am indebted to the ESPMH for sponsoring me through their 2007 Young Scholars' first prize award to present this paper at their annual conference. This work was originally funded through a Rubicon fellowship (grant 825.06.026) awarded by the Board of the Council for Earth and Life Sciences (ALW) of the Netherlands Organisation for Scientific Research (NWO). The funder had no influence on the design, analysis, and interpretation of (and the decision to submit) this work.

Open Access This article is distributed under the terms of the Creative Commons Attribution Noncommercial License which permits any noncommercial use, distribution, and reproduction in any medium, provided the original author(s) and source are credited.

\section{References}

Acheson, D. 1988. Public health in England. The Report of the Committee of Inquiry into the Future Development of the Public Health Function. Cmnd 289. London: HMSO.

Anand, S., and K. Hanson. 1997. Disability-adjusted life years: A critical review. Journal of Health Economics 16: 685-702.

Anand, S., and K. Hanson. 1998. DALYs: Efficiency versus equity. World Development 26: 307-310.

Appiah, K.A. 2005. The ethics of identity. Princeton: Princeton University Press.

Arah, O.A. 2005. Performance reexamined. Concepts, content and practice of measuring health system performance. Amsterdam: Buijten and Schipperheijn Publishing, and Academic Medical Center, University of Amsterdam.

Arah, O.A. 2009. On the evaluative space for measuring public health performance. In The philosophy of public health, ed. A. Dawson. Aldershot: Ashgate Publishing Ltd (in press).

Arah, O.A., U.C. Ogbu, and C.E. Okeke. 2008. Too poor to leave, too rich to stay? Developmental and global health correlates of physician migration to the United States, Canada, Australia, and the United Kingdom. American Journal of Public Health 98: $148-154$. 
Arah, O.A., and G.P. Westert. 2005. Correlates of health and healthcare performance: Applying the Canadian health indicators framework at the provincial-territorial level. BMC Health Services Research 5: 76.

Arah, O.A., G.P. Westert, J. Hurst, and N.S. Klazinga. 2006. A conceptual framework for the OECD Health Care Quality Indicators Project. International Journal for Quality in Health Care 18(Suppl 1): 5-13.

Ball, R. 2001. Individualism, collectivism and economic development. Annals of the American Academy of Political and Social Science 573: 57-84.

Beauchamp, D.E. 1975. Public health: Alien ethic in a strange land? American Journal of Public Health 65: 1338-1339.

Beauchamp, D.E. 1983. What is public about public health? Health Affairs 2: 76-87.

Boorse, C. 1975. On the distinction between disease and illness. Philosophy and Public Affairs 5: 49-68.

Boorse, C. 1977. Health as a theoretical concept. Philosophy of Science 44: 542-573.

Boorse, C. 1997. A rebuttal on health. In What is disease? (Biomedical ethics reviews), ed. J.M. Humber and R.F. Almeder. Totowa, New Jersey: Humana Press.

Case, A., A. Fertig, and C. Paxson. 2005. The lasting impact of childhood health and circumstance. Journal of Health Economics 24: 365-389.

Coburn, D., K. Denny, E. Mykhalovskiy, P. McDonough, A. Robertson, and R. Love. 2003. Population health in Canada: A brief critique. American Journal of Public Health 93: 392-396.

Copas, J.B. 1973. Randomization models for the matched and unmatched $2 \times 2$ tables. Biometrika 60: 476 .

Culyer, A.J. 1995. Need: The idea won't do-but we still need it. Social Science and Medicine 40: 727-730.

Dawson, A., and M. Verweij (ed.). 2007. Ethics, prevention and public health. Oxford: Oxford University Press.

Evans, R.G., and G.L. Stoddart. 1990. Producing health, consuming health care. Social Science and Medicine 31: 1347-1363.

Evans, R.G., and G.L. Stoddart. 2003. Consuming research, producing policy? American Journal of Public Health 93: 371-379.

Friedman, D.J., and B. Starfield. 2003. Models of Population Health: Their Value for US Public Health Practice, Policy, and Research. American Journal of Public Health 93: 366-369.

Greenland, S. 2000. Causal analysis in the health sciences. Journal of the American Statistical Association 95: 286-289.

Greenland, S. 2005. Epidemiologic measures and policy formulation: Lessons from potential outcomes. Emerging Themes in Epidemiology 2: 5.

Greenland, S., and J.M. Robins. 1986. Identifiability, exchangeability, and epidemiological confounding. International Journal of Epidemiology 15: 413-419.

Hume, D. 1739. A treatise of human nature (Reprint 1988 ed.). Oxford: Claredon Press.

Hume, D. 1748. An enquiry concerning human understanding (Reprint 1988 ed.). LaSalle, IL: Open Court Press.

Institute of Medicine. 1998. Summarizing population health: Directions for the development and application of population metrics. Washington, DC: National Academies Press.

Irwin, A., N. Valentine, C. Brown, R. Loewenson, O. Solar, H. Brown, T. Koller, and J. Vega. 2006. The commission on social determinants of health: Tackling the social roots of health inequities. PLoS Medicine 3: e106.

Jamrozik, K., and M. Hobbs. 2002. Medical care and public health. In Oxford textbook of public health, ed. R. Detels, J. McEwen, R. Beaglehole, and H. Tanaka. Oxford: Oxford University Press.

Khushf, G. 2007. An agenda for future debate on concepts of health and disease. Medicine, Health Care and Philosophy 10: 19-27.
Kindig, D., and G. Stoddart. 2003. What is population health? American Journal of Public Health 93: 380-383.

Kuh, D., and Y. Ben-Shlomo (ed.). 2004. A life course approach to chronic disease epidemiology, 2nd ed. Oxford: Oxford University Press.

Kuh, D., Y. Ben-Shlomo, J. Lynch, J. Hallqvist, and C. Power. 2003. Life course epidemiology. Journal of Epidemiology and Community Health 57: 778-783.

Lalonde, M. 1974. A new perspective on the health of Canadians. Ottawa: Office of the Canadian Minister of National Health and Welfare.

Lee, J.W. 2005. Public health is a social issue. Lancet 365: 10051006.

Lewis, D. 1973. Causation. Journal of Philosophy 70: 556-567.

Mackenbach, J.P. 2006. The origins of human disease: A short story on "where diseases come from". Journal of Epidemiology and Community Health 60: 81-86.

Maldonado, G., and S. Greenland. 2002. Estimating causal effects (with discussion). International Journal of Epidemiology 31: 422-429.

Marmot, M. 2006. Health in an unequal world. Lancet 368: 2081-2094.

Mathers, C.D., K.M. Iburg, J.A. Salomon, A. Tandon, S. Chatterji, B. Ustun, and C.J.L. Murray. 2004. Global patterns of healthy life expectancy in the year 2002. BMC Public Health 4: 66.

Mathers, C.D., C.J. Murray, M. Ezzati, E. Gakidou, J.A. Salomon, and C. Stein. 2003. Population health metrics: Crucial inputs to the development of evidence for health policy. Population Health Metrics 1: 6.

McDowell, I., R.A. Spasoff, and B. Kristjansson. 2004. On the classification of population health measurements. American Journal of Public Health 94: 388-393.

Mechanic, D. 2003. Who shall lead: Is there a future for population health? Journal of Health Politics, Policy and Law 28: 421-442.

Murray, C.J. 1994. Quantifying the burden of disease: The technical basis for disability-adjusted life years. Bulletin of the World Health Organization 72: 429-445.

Murray, C.J., and D.B. Evans (ed.). 2003. Health system performance assessment: Debates, methods, and empiricism. Geneva: World Health Organization.

Murray, C.J., J. Frenk, D. Evans, K. Kawabata, A. Lopez, and O. Adams. 2001. Science or marketing at WHO? A response to Williams. Health Economics 10: 277-282.

Murray, C.J., and A.D. Lopez. 1994. Quantifying disability: Data, methods and results. Bulletin of the World Health Organization 72: 481-494.

Murray, C.J., A.D. Lopez, and D.T. Jamison. 1994. The global burden of disease in 1990: Summary results, sensitivity analysis and future directions. Bulletin of the World Health Organization 72: 495-509.

Murray, C.J.L., J.A. Salomon, C.D. Mathers, and A.D. Lopez (ed.). 2002. Summary measures of population health: Concepts, ethics and applications. Geneva: World Health Organization.

Nordenfelt, L. 1986. Health and disease: Two philosophical perspectives. Journal of Epidemiology and Community Health 40: 281284.

Nordenfelt, L. 1995. On the nature of health: An action-theoretic approach. Dordrecht: Kluwer Academic Publishers.

Nordenfelt, L. 1998. On medicine and health enhancement-towards a conceptual framework. Medicine, Health Care and Philosophy 1: $5-12$.

Nordenfelt, L. 2001. On the goals of medicine, health enhancement and social welfare. Health Care Analysis 9: 15-23.

Nordenfelt, L. 2007. The concepts of health and illness revisited. Medicine, Health Care and Philosophy 10: 5-10.

Nussbaum, M.C., and A.K. Sen (ed.). 1993. The quality of life. New York: Oxford University Press. 
O’Neill, J. (ed.). 1973. Modes of individualism and collectivism. New York: St. Martin's Press.

Pana, A., and A. Muzzi. 2004. Population health and individual health. Igiene Sanità Pubblica 60: 291-298.

Pearl, J. 1995. Causal diagrams for empirical research. Biometrika 82: 669-710.

Pearl, J. 2000. Causality: Models, reasoning and inference. Cambridge: Cambridge University Press.

Rose, G. 1985. Sick individuals and sick populations. International Journal of Epidemiology 14: 32-38.

Rose, G. 1992. The strategy of preventive medicine. Oxford: Oxford University Press.

Schramme, T. 2007. A qualified defence of a naturalist theory of health. Medicine, Health Care and Philosophy 10: 11-17.

Sen, A.K. 1985. Commodities and capabilities. Amsterdam: NorthHolland.

Sen, A.K. 1992. Inequality reexamined. Oxford: Oxford University Press.

Spirtes, P., C. Glymour, and R. Scheines. 1993. Causation, prediction, and search. New York: Springer-Verlag.
Spohn, W. 1980. Stochastic independence, causal independence, and shieldability. Journal of Philosophical Logic 9: 73-79.

Szreter, S. 2003. The population health approach in historical perspective. American Journal of Public Health 93: 421-431.

van Oers, J.A.M. (ed.) 2002. Health on course? The 2002 Dutch Public Health Status and Forecasts Report. Houten: Bohn Stafleu Van Loghum.

Verweij, M., and A. Dawson. 2007. The meaning of "public" in public health. In Ethics, prevention and public health, ed. A. Dawson and M. Verweij. Oxford University Press: Oxford.

Weale, A.P. 1981. Representation, individualism and collectivism. Ethics 91: 457-465.

Williams, A. 2000. Science or marketing at WHO? A commentary on "World Health Report 2000". Health Economics 10: 93-100.

World Bank. 1993. World Development Report 1993: Investing in health. Washington, DC: The World Bank.

World Health Organization. 2000. The World Health Report 2000. Health systems: Improving performance. Geneva: WHO. 